\title{
The report on the co-occurrence of two different rare anatomic variations of the plantaris muscle tendon on both sides of an individual
}

\author{
Ł. Olewnik ${ }^{1}$, G. Wysiadecki ${ }^{1}$, M. Polguj ${ }^{2}$, M. Topol ${ }^{1}$ \\ ${ }^{1}$ Department of Normal and Clinical Anatomy, Interfaculty Chair of Anatomy and Histology, \\ Medical University of Lodz, Poland \\ ${ }^{2}$ Department of Angiology, Interfaculty Chair of Anatomy and Histology, Medical University of Lodz, Poland
}

[Received: 20 June 2016; Accepted: 26 September 2016]

\begin{abstract}
The plantaris muscle usually begins with a short and small muscle belly on the popliteal surface of the femur and on the knee joint capsule. It continues distally to form a long and thin tendon typically fixed to the calcaneal tuberosity. However, the course and the insertion of the plantaris muscle is variable, which may influence the development of Achilles tendinopathy. The plantaris tendon may also be used for reconstruction of tendons and ligaments, such as talofibular and calcaneofibular ligament.

In literature review no data concerning the co-occurrence of anatomic variations of the plantaris muscle tendon in different individuals has been found. This report presents a rare variant of the plantaris muscle insertion into the deep crural fascia on the left leg and absence of the plantaris muscle on the right leg of the same individual. (Folia Morphol 2017; 76, 2: 331-333)
\end{abstract}

Key words: calcaneal (Achilles) tendon, deep crural fascia, plantaris muscle, plantaris tendon

\section{INTRODUCTION}

The plantaris muscle (PM) has a short, slim and spindle-shaped, muscle belly with a long tendon [11]. The origin of the muscle is located on the popliteal surface of the femur and on the knee joint capsule, deep to the lateral head of the gastrocnemius muscle [3]. The muscle belly continues distally with a long and thin tendon running between the medial head of the gastrocnemius muscle and the soleus muscle. On its further course, the plantaris tendon typically travels along the medial border of the calcaneal (Achilles) tendon [16].

There are several anatomic variations of the PM insertion $[2,12,18]$. Rare cases of absence of the PM were also recorded $[6,12,15]$. The distal course and the variations of insertion of the PM may play an important role in pathogenesis of the Achilles tendinopathy $[1,10,12,17,18]$. Furthermore, with the extremely high density of proprioceptive receptors, the PM may be a 'transmitter' of information on the foot position and the movements [11].

In this report we describe rare variants of the insertion of the PM to the deep crural fascia of the right limb, co-existing with the absence of the PM on the left side. To our knowledge, this is the first description of such a case.

\section{CASE REPORT}

A 58-year-old female cadaver was subjected to routine anatomical dissection for research and teach- 


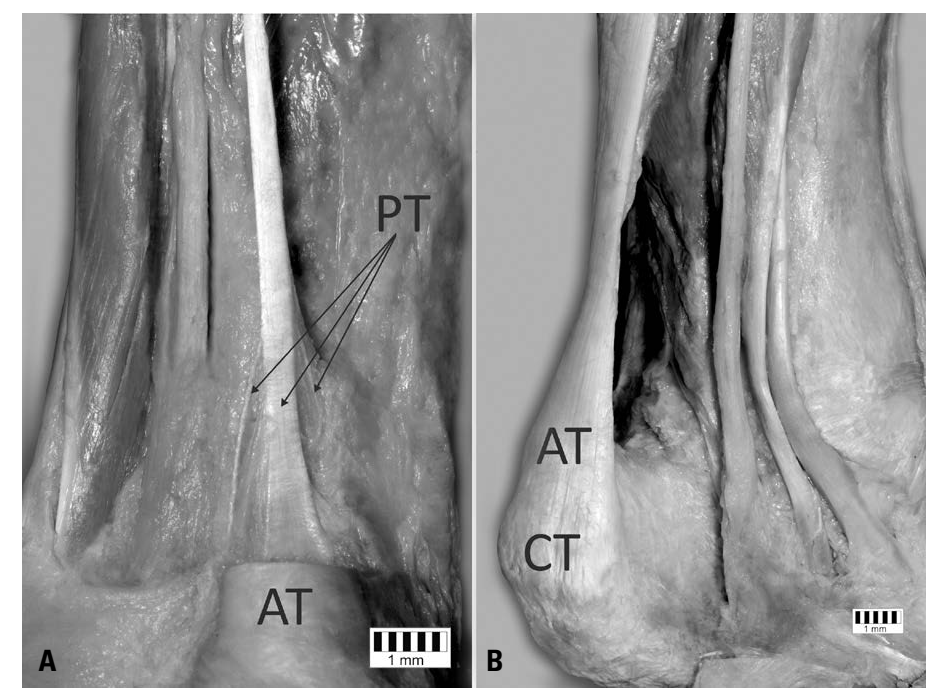

Figure 1. Two rare anatomic variants of the plantaris muscle on both sides of the same cadaver; A. Posterior view of the right leg. Atypical insertion of the plantaris tendon (PT) to the deep crural fascia (marked by black arrows); B. Posteromedial view of the left leg. Absence of the plantaris muscle; AT — calcaneal (Achilles) tendon; CT — calcaneal tuberosity.

ing purposes at the Department of Normal and Clinical Anatomy of Medical University of Lodz. During the dissection of the lower limbs, a very rare variant of the PM insertion to the deep crural fascia on the right leg (Fig. 1A), as well as the absence of the PM on the left leg, were found (Fig. 1B).

The next stage of the procedure involved a detailed assessment of the PM muscle belly and the course of its tendon. The origin of the PM was located on the knee joint capsule under the lateral head of the gastrocnemius muscle. The muscle belly ran between the medial head of the gastrocnemius muscle and the soleus muscle, then it coursed towards the medial side of the leg, anteriorly to the Achilles tendon. The distance between the Achilles tendon and the plantaris tendon was $2.4 \mathrm{~mm}$. The insertion of the plantaris tendon was located on the deep crural fascia (Fig. 1A). This type of plantaris tendon attachment was characterised with the presence of the extension point (the point where the plantaris tendon begins to expand into its insertional footprint) at the distal part of the tendon (Fig. 1A). The distance between the extension point and the calcaneal tuberosity was $41.2 \mathrm{~mm}$, the tendon width at this point was $4.85 \mathrm{~mm}$, and the tendon thickness was $0.5 \mathrm{~mm}$.

Upon photographic documentation, the PM was cut out and subjected to further measurements. The muscle was measured by an electronic calliper (Mitutoyo Corporation, Kawasaki-shi, Kanagawa, Japan). Each measurement was made with the accuracy of up to $0.1 \mathrm{~mm}$. The length of the muscle belly was
$103.8 \mathrm{~mm}$ and its thickness was $8.2 \mathrm{~mm}$. The width of the muscle belly in the thickest point was $21.6 \mathrm{~mm}$. The width of the tendon upon passing the muscle belly was $3.7 \mathrm{~mm}$. The total length of the muscle was $391 \mathrm{~mm}$. The ratio between the tendon length and the overall length of the muscle was $79 \%$.

\section{DISCUSSION}

The PM may be regarded as the vestigial remains of a primitive flexor of the toes [5]. According to this model, the calcaneal tuberosity has become a 'node' or a 'spacer' and both parts of a primitive flexor (the plantaris tendon and the plantar aponeurosis) are attached to it, but they are not linked to each other [5]. The theory presented by Cruveilhier also suggests that the change in the foot position (perpendicular to the leg) was a result of the loss of the plantaris insertion into the plantar aponeurosis [4]. Cruveilhier concluded that due to the loss of the PM insertion to the plantar aponeurosis, a secondary insertion into the calcaneus developed. The human upright posture caused the hind foot to drop to the ground, which provides increased stability to two-legged weight bearing [4].

Rare cases of the absence of the PM have been reported in the literature. In the study carried out by Harvey et al. [6] the PM did not occur in $19 \%$ of the lower limbs, while Simpson et al. [15] concluded that the absence of the PM oscillated between $7 \%$ and $20 \%$. In our earlier studies we detected the absence of the PM in 2 out of 50 lower limbs, which represented $4 \%$ [12]. 
The insertion of the PM may be variable $[2,3,12$, 18]. Sterkenburg et al. [18], based on dissections of 107 lower limbs, created a classification of the insertion of the PM tendon. The classification included 9 types, of which the most frequent was the 'medial insertion of the plantaris tendon onto calcaneus' [18]. In the studies of Sterkenburg et al. [18], the attachment of the plantaris tendon to the deep crural fascia occurred in only one limb (0.9\%). Such a type of insertion is similar to that described in our report. However, in the presented case, the plantaris tendon ran anteriorly to the Achilles tendon and gave thin tendinous bundles on both sides of the main tendon fibres (Fig. 2A), whereas in the study of Sterkenburg et al. [18] it was located more medially. Some authors hypothesize that there may be a striking similarity between the PM and the palmaris longus on the forearm [19].

The plantaris tendon may be used as a graft for hand tendon reconstruction [15]. The PM tendon grafts may be used for the reconstruction of the anterior talofibular and calcaneofibular ligaments [7, 13]. Shuhaiber et al. [14] suggested the possibility of using the plantaris tendon grafts for the reconstruction of the flexor muscle tendons in the upper limb or even for atrioventricular valve repair. However, anatomical variations of PM may potentially complicate the successful harvesting procedures. Clinically, the PM may also play an important role in the pathogenesis of the Achilles tendinopathy $[1,10,17,18]$. Moreover, the rupture of the plantaris tendon may cause symptoms similar to deep vein thrombosis $[8,9]$. In case of musculoskeletal injuries associated with ruptures of the PM tendon, treatment with anticoagulants may cause potential bleeding and fascial parochialism syndrome [9]. Thus, high definition ultrasound or magnetic resonance imaging tests should be carried out in order to diagnose the cause of the pain at the medial side of the lower leg $[8,9]$.

\section{CONCLUSIONS}

Rare anatomic variations of the PM may co-occur on both sides of an individual. Surgical procedures using plantaris tendon may be hindered by the absence of or atypical insertion of the PM.

\section{REFERENCES}

1. Alfredson $\mathbf{H}$. Midportion Achilles tendinosis and the plantaris tendon. Br J Sports Med. 2011; 45(13): 1023-1025, doi: 10.1136/bjsports-2011-090217.

2. Anson BJ, McVay CB. Surgical Anatomy. Volume 2. Saunders Company, Philadelphia: pp. 1186-1189.
3. Bergman RA, Afifi AK, Miyauchi R (2015) Illustrated Encyclopedia of Human Anatomic Variation: Opus I: Muscular System: Alphabetical Listing of Muscles. [online]. http:// www.anatomyatlases.org/AnatomicVariants/MuscularSystem/Text/P/29Plantaris.shtml. (accessed March 2016).

4. Cruveilhier J. Anatomie descriptive. 1st ed. Paris, Becket Jeune. 1834: pp 262-263.

5. Daselar EH, Anson BJ. The Plantaris Muscle: An Anatomical Study of 750 Specimens. J Bone Joint Surg. 1943; 25: 822-827.

6. Harvey FJ, Chu G, Harvey PM. Surgical availability of the plantaris tendon. J Hand Surg Am. 1983; 8(3): 243-247, indexed in Pubmed: 6875222.

7. Kotian SR, Sachin KS, Bhat KMR. Bifurcated plantaris with rare relations to the neurovascular bundle in the popliteal fossa. Anat Sci Int. 2013; 88(4): 239-241, doi: 10.1007/ s12565-013-0184-z, indexed in Pubmed: 23771697.

8. Kwinter D, Lagrew J, Kretzer J, et al. Unilateral Double Plantaris Muscle: A Rare Anatomical Variation. Int J Morphol. 2010; 28(4): 1097-1099, doi: 10.4067/s071795022010000400018.

9. Lopez GJ, Hoffman RS, Davenport M. Plantaris rupture: a mimic of deep venous thrombosis. J Emerg Med. 2011; 40(2): e27-e30, doi: 10.1016/j.jemermed.2007.12.027, indexed in Pubmed: 19150191.

10. Masci L, Spang C, van Schie HTM, et al. How to diagnose plantaris tendon involvement in midportion Achilles tendinopathy - clinical and imaging findings. BMC Musculoskelet Disord. 2016; 17: 97, doi: 10.1186/s12891-016-0955-5, indexed in Pubmed: 26912241.

11. Moore KL, Dalley AF, Agur AMR. Clinically Oriented Anatomy. 6th edn. Lippincott Williams \& Wilkins, Philadelphia. 2010: p. 600 .

12. Olewnik $Ł$, Wysiadecki G, Polguj M, et al. Anatomic study suggests that the morphology of the plantaris tendon may be related to Achilles tendonitis. Surg Radiol Anat. 2017; 39(1): 69-75, doi: 10.1007/s00276-016-1682-1, indexed in Pubmed: 27155667.

13. Pagenstert G, Valderrabano V, Hintermann B. Lateral ankle ligament reconstruction with free plantaris tendon graft. Tech Foot Ankle Surg. 2005; 4(2): 104-112, doi: 10.1097/01. btf.0000152574.09654.80.

14. Shuhaiber JH, Shuhaiber HH. Plantaris tendon graft for atrioventricular valve repair: a novel hypothetical technique. Tex Heart Inst J. 2003; 30(1): 42-4; discussion 44, indexed in Pubmed: 12638670.

15. Simpson SL, Hertzog MS, Barja RH. The plantaris tendon graft: an ultrasound study. J Hand Surg Am. 1991; 16(4): 708-711, indexed in Pubmed: 1880370.

16. Spina AA. The plantaris muscle: anatomy, injury, imaging, and treatment. J Can Chiropr Assoc. 2007; 51(3): 158-165, indexed in Pubmed: 17885678.

17. van Sterkenburg MN, Kerkhoffs GM, van Dijk CN. Good outcome after stripping the plantaris tendon in patients with chronic mid-portion Achilles tendinopathy. Knee Surg Sports Traumatol Arthrosc. 2011; 19(8): 1362-1366, doi: 10.1007/ s00167-011-1514-0, indexed in Pubmed: 21541711.

18. van Sterkenburg MN, Kerkhoffs GM, Kleipool RP, et al. The plantaris tendon and a potential role in mid-portion Achilles tendinopathy: an observational anatomical study. J Anat. 2011; 218(3): 336-341, doi: 10.1111/j.14697580.2011.01335.x, indexed in Pubmed: 21323916.

19. White WL. The unique, accessible and useful plantaris tendon. Plast Reconstr Surg Transplant Bull. 1960; 25: 133-141, indexed in Pubmed: 13844415. 